\title{
The pipe material and improvement state analysis of technological processes for laying main gas pipelines
}

\author{
Narine Pirumyan ${ }^{1 *}$, Migran Stakyan ${ }^{1}$, and Hmayk Khazaryan ${ }^{2}$ \\ ${ }^{1}$ National University of Architecture and Construction of Armenia, Yerevan, Republic of Armenia \\ 2 "Gazprom Armenia" CJSC, Yerevan, Republic of Armenia
}

\begin{abstract}
The change in the structural state of the gas pipes' weld material at different seam cross-sections have been considered. The classification of external and internal defects of the joint material caused by the influence of different types of factors, most significant of which are the material defects in the transition zone of the joint to the pipe base metal. The analysis of atmospheric effects on the pipeline welds materials initiating adsorption and electrochemical processes in the metal microstructure that cause corrosion on the seam outer surface is given. Taking into account the non-stationary mode of pipes loading due to fluctuations in internal gas pressure, corrosion-fatigue damage is also added to these material defects, which cause the fatigue cracks development in the material, leading to a violation of the system tightness and even to welds destruction. The structure of a mobile device is proposed for performing a complex of technological operations for assembling large-diameter ground gas pipeline and for ensuring installation accuracy and maintenance processing of the welded pipes' edges, automatic welding along the seam perimeter, cleaning, grinding and hardening of the seam material outer surface, applying a protective coating against atmospheric influences. The device facilitates the work of installation staff, increases the reliability and bearing capacity of the gas transmission system installed in difficult terrain.
\end{abstract}

\section{Introduction}

The development of basic industries, agriculture and social development of countries requires further expansion of the gas transportation system (GTS), which over the past decade, interstate and regional character overcoming difficult relief-climatic zones and water (sea) spaces. At the same time, an important technological task is to create a network of main pipelines using large-diameter steel pipes connected by welded seams, and this process is constantly being improved in order to speed up the laying time, ensure the necessary operational reliability and extend the service life of pipeline structural elements $[1,2,3]$.

\footnotetext{
* Corresponding author: pirumyannarine@gmail.com
} 
According to the statistical data and results of technical inspection and examination, it was found that about $70 \ldots 75 \%$ of failures and damage to the GTS elements are fatigue-related, and $20 . .25 \%$ of failures are due to corrosion. The continuous increase in the volume of emissions of industrial waste and transport gases into the atmosphere increases annually, which leads to an increase in the corrosion effect on metal material structures for various purposes, including GTS. Corrosion losses are estimated at up to $30 \%$ of structural steels and alloys weight in the form of unacceptably deformed or destroyed structural elements that need repair or replacement, of which about $5 . . .7 \%$ permanently disappear in the form of corrosive dust or various chemical compounds. This dictates the need for a detailed study of corrosion processes in GTS structures and the development of effective anti-corrosion procedures in order to minimize the volume of structural steels and alloys losses, the cost of which tends to increase due to the expansion of the GTS interstate network $[4,5,6]$.

\section{Corrosion phenomena in GTS structural elements' materials}

Corrosion of structural steels and alloys is usually manifested in two types - chemical and electrochemical $[4,5]$. A more common type is electrochemical corrosion, when the contact occurs with moist air, water, salt and acid solutions, etc., in which anode and cathode interaction processes occur in metal microstructures and liquid electrolytes, while the intensity and speed of the corrosion process depends on the hydrogen index of the liquid $\mathrm{pH}$. The most significant destruction type is the adsorption of $\mathrm{O}_{2}$ and $\mathrm{H}_{2}$ in ionic, atomic or molecular states in the surface layer of metal and the creation of oxide and hydride phases that cause embrittlement and delamination of this layer and the appearance of surface microcracks. As a result, there is a significant decrease in the physical and mechanical characteristics of the alloy under static and cyclic loading [7]. Since the process of corrosion action is continuous, there are no physical limits of strength and endurance, which makes it necessary to determine their values to fix the service life of the structure in the interval of the durations of the $N=5 \cdot 10^{4} \cdots 8 \cdot 10^{8}$ loading cycles and to obtain the corresponding experimental functions. But as fatigue tests show, the gradient of these functions varies in the $N$ interval, due to the different nature of the corrosion failure mechanism $[8,9,10]$.

In many studies, the hypothesis of adsorption - electrochemical corrosion destruction has been discussed, more precisely representing these changes in the corrosion process. Under more common loading conditions (re-static and cyclic), local micro-fractures and the first fatigue micro-cracks also appear in the areas where dislocations reach the metal surface. The anodic processes occurring inside microcracks of material promote their growth at high cyclic overvoltage, while the adsorption process increases and prevails. At low overvoltage, cyclic micro-damages mainly occur due to electrochemical processes, when overvoltage destroy the oxide micro-layers of the surface and promote the infiltration of the corrosive environment into new metal layers $[5,11,12,13]$.

\section{Structural condition, defects and damage of the pipelines' welded seam metal}

The operating GTS network conditions are characterized by the internal gas pressure [11], which creates a static or variable stress state in the system, and a variable temperature regime $(-45 \ldots+50 \circ \mathrm{C})$, and climatic conditions of the region (topography, solar radiation, atmospheric pressure, wind, humidity, precipitation, etc.), forming a natural corrosive environment, which can cause irreversible physical and chemical changes in the welded joint 
and base metal pipeline corrosion due to leakage, sorption, erosion and other processes, which ultimately lead to disease, loss of strength and structural failure [9, 10, 12, 14].

The pipeline network is formed as a rule by the use of circular butt welds, which are the main type of GTS welded joints. In this case, the weld and the base metal in the cross section have a layered microstructure consisting of several sections (Fig. 1) [4, 15].

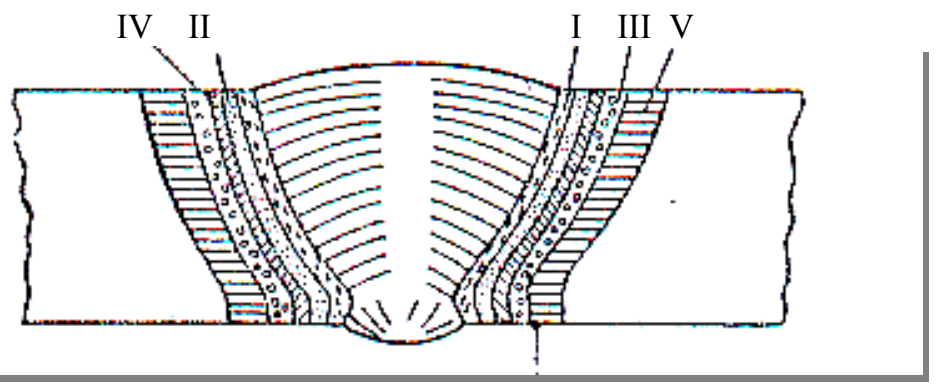

Fig. 1. Microstructural layers in the contact zone of the weld and the base metal

The transition zone from the weld to the base metal is the most loaded due to the action of residual tensile stresses. The physical and mechanical state of this zone, which determines the bearing capacity of the welded joint, is formed under the influence of an alternating temperature field and its gradient, which accompany welding and vary significantly. At the same time, it is possible to note the sections I-IV (Fig.1), in which some constancy of the specified state is observed and only as the distance from the center of the seam is removed, the initial fine-grained microstructure of the base metal is established in section IV (Table 1).

Table 1. Changes in the physical and mechanical state in different sections of the transition of the weld to the base metal

\begin{tabular}{|c|c|c|c|c|}
\hline $\begin{array}{l}\text { Secti } \\
\text { on no. }\end{array}$ & $\begin{array}{l}\text { Processes occurring } \\
\text { within the section }\end{array}$ & $\begin{array}{c}\text { Temperature } \\
\text { in } \\
\text { the section, } \\
{\left[{ }^{\mathrm{O}} \mathrm{C}\right]}\end{array}$ & $\begin{array}{c}\text { Section } \\
\text { thickness, } \\
{[\mathrm{mm}]}\end{array}$ & $\begin{array}{l}\text { Microstructural } \\
\text { changes in the } \\
\text { cross section }\end{array}$ \\
\hline I & High thermal effect & $1000 \cdots 1100$ & $\sim 2.0$ & $\begin{array}{l}\text { Coarse-grained } \\
\text { microstructure } \\
\text { formation } \\
\end{array}$ \\
\hline II & $\begin{array}{l}\text { Full cross section } \\
\text { recrystallization }\end{array}$ & $850 \cdots 900$ & $0.5 \cdots 2.0$ & $\begin{array}{l}\text { Fine-grained } \\
\text { microstructure } \\
\text { formation }\end{array}$ \\
\hline III & $\begin{array}{l}\text { Incomplete cross } \\
\text { section } \\
\text { recrystallization }\end{array}$ & $720 \cdots 850$ & $0.5 \cdots 1.0$ & $\begin{array}{l}\text { Partial grinding of } \\
\text { the microstructure }\end{array}$ \\
\hline IV & $\begin{array}{c}\text { Low thermal section } \\
\text { release }\end{array}$ & $500 \cdots 550$ & $2.0 \cdots 5.0$ & $\begin{array}{l}\text { Completion of the } \\
\text { fine-grained } \\
\text { microstructure } \\
\text { formation process }\end{array}$ \\
\hline V & Thermal site aging & $250 \cdots 350$ & $4.0 \cdots 10.0$ & $\begin{array}{c}\text { Microstructure is } \\
\text { actually } \\
\text { unchanged }\end{array}$ \\
\hline
\end{tabular}

Of all types of welded joints, butt joints have the greatest endurance, but even in this case, the stress concentration and residual tensile stresses that occurred during the formation of the 
joint in this zone significantly affect the fatigue strength of the joint. Even if the welding technology is performed correctly, and there are no defects, cracks, or non-metallic inclusions, the weakest link that determines the bearing capacity of the joint is the seam transition section to the base metal (Fig.1) and only if there are significant defects and damage in another section of the joint, the residual tensile stresses can be moved in this section [12, 14].

The technological process of welding has its own characteristics and the quality of its performance depends on the following factors:

- poor quality of pipe material,

- inaccuracies in the pretreatment of seam edges,

- presence of delamination and corrosion layer on the surfaces of the seam edges,

- stress concentration in the transition zone of the weld to the base metal of the pipe,

- violation of the welding mode - fluctuations in the voltage of the electric current, changes in the speed of movement and location, as well as the number of passes of the electrode,

- low qualification of service personnel.

These defects, if they are unfavorably located in the seam section, can also violate the tightness of the pipeline, so after performing welding operations, additional technological operations are mandatory: mechanical cleaning and grinding of the weld contour, strengthening of the joint and applying an anti-corrosion coating to increase the tightness, corrosion resistance and strength of the welded joint.

The environmental impact on the GTS elements increases in the presence of these defects and technological omissions in the welded joints of pipelines, where corrosion processes are initiated, leading to the destruction of the welds $[6,12]$.

The main types of corrosion failure of welded joints include [16]:

1. Solid or general corrosion - can be evenly distributed over the entire surface of the welded joint and the role of the stress state is secondary.

2. Local corrosion - more dangerous than the first type and depends on the stress state, the action of which can lead to a sudden failure of the pipeline.

3. Static and fatigue corrosion - are the most dangerous types of destruction under the combined action of a corrosive environment and a stress state caused by extreme static or re-static and cyclic loads.

\section{Methods for improving the GTS welded joints' efficiency}

Increasing the bearing capacity, corrosion resistance and fatigue strength of GTS welded joints is mainly implemented by materials science and technological methods, which include the following procedures $[16,17,18,19,20,21]$ :

- selection of the type and grade of the base metal of steel pipes, as well as the hardening method that ensures the strength of the welded joint with minimal costs of the welding process and low cost of the pipe material;

- reducing the stress concentration of the mech. treatment of the seam surface and creation of a smooth transition zone to the base metal;

- complete formation of the volume of the weld and the exclusion of non-welding in its lower part in order to prevent a new zone of stress concentration and micro cracks;

- cleaning of the surface layers of the weld and the transition zone from non-metallic coatings and inclusions that have arisen during the welding process;

- creation of residual compressive stresses in the weld zone by methods of plastic deformation of the surface layer of the weld and the transition zone to the base metal;

- application of new protective coatings made of polymer composite materials that increase the corrosion and crack resistance of welds. 
The structural strength of the GTS pipelines in the weld zone significantly depends on the mechanical characteristics of the metal to plastic deformation and the performance of the process of strengthening the welded joint, as well as the type of heat treatment. For these steels, plastic deformation of the surface layers of low-carbon steels can increase their endurance limits by $1.5 \ldots 2.0$ times. In this case, the weld and the base metal act as a joint force system with mutual penetration of their microstructural layers in the contact zone.

Among the types of hardening, the most technologically advanced and easily implemented is the method of plastic deformation by rolling rollers, which create a uniform layer of deformation on the surface of the welded joint. The resulting residual compressive stresses $\sigma_{\text {compr.max }}$ (Fig. 2, curve 2) compensate for the effect of residual tensile stresses $\sigma_{\text {tens.max }}$ (Fig. 2, curve 1), creating a favorable initial stress state (Fig. 2, curve 3) for receiving operating stresses.

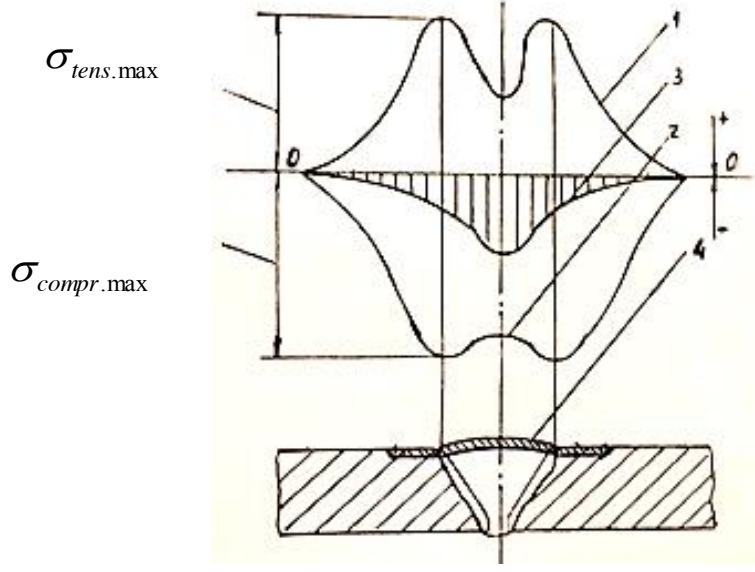

Fig. 2. Stress distribution in the welded joint area: 1,2 - residual tensile and compressive stresses, respectively, 3 - initial total voltages before the GTS operating mode start, 4 - plastically deformed surface layer

Surface plastic deformation has a positive effect on the bearing capacity of welded joints also under the influence of negative temperatures $\left(t_{3}=0 \cdots-50^{\circ} \mathrm{C}\right)$ and corrosive environments, in fact, being a universal technology for increasing the corrosion-fatigue strength of these joints. Another important advantage of this technology is its implementation by mechanisms and devices that have a simple, reliable and portable construction that allows to strengthen the weld in the field, directly during welding operations and laying the GTS pipeline [21, 22, 23, 24].

The usage of new protective coatings made of polymer composite materials, due to their high adhesive properties, not only increase corrosion resistance and tightness, but also by filling micropores and cracks on the surface of the weld, smooth out the effect of stress concentration and contribute to increasing the fatigue strength of welded joints.

\section{The fulfilment of welding work in the main gas pipelines' ground laying}

The processes of marking, installation and assembly of main gas pipelines are carried out in conditions of difficult terrain in the absence of the necessary stationary technological 
equipment and transport infrastructure, which forces the entire complex of the technological process of welding pipes to be carried out using special mobile devices. Fig. 3 shows a design diagram of such a device, which is installed and fixed in the pipe welding zone and, with the help of gripping units (threaded connection), approximates and centers the edges of the welded pipes. It is driven (asynchronous motor brand $\left.4 A 112 \mathrm{M}, P_{\ni}=2.2 \mathrm{~kW}, n_{\ni}=705 \mathrm{rpm}\right)$ and cylindrical gear $\left(u_{n}=10\right)$, on the big wheel which has two round semi levers, which one end is fixed on the wheel by means of a movable cylindrical compound, and the second end of the movable installed the bolt to adjust the relative location of semi levers. The semi levers are equipped with two grinding wheels and deforming rollers with nodes for adjusting the radial gap between them and the outer surface of the weld. On one of the semi levers there is a unit for cleaning and applying a protective coating on the seam surface, and on the other - a cutter unit for the final mechanical processing of the pipe edges before the weld application, which is also an adjustable node in the radial direction.
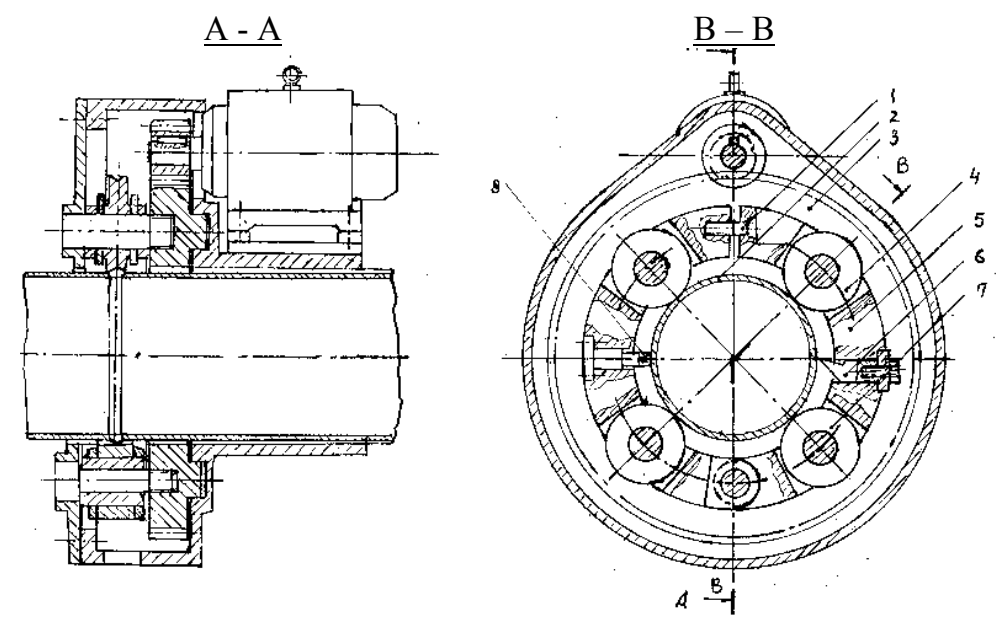

Fig. 3. Constructive scheme of a mobile welding device: 1- control threaded connection, 2-welded pipe, 3-large gear wheel, 4 - grinding wheel, 5-round semi-lever, 6 - assembly for the mech. processing of pipe edges, 7- deforming roller, 8-assembly for cleaning waste mechanical processing and application of protective coating

After the mechanical processing of the pipe edges the mobile device is moved to the starting position and an automatic welding machine of the PRD 100 brand [25] is installed on the edges along the perimeter of the seam. The device is compact (weight $-8 \mathrm{~kg}$ ) and is designed for welding pipes with a $D=100 \cdots 600 \mathrm{~mm}$ diameter and can work in a narrow space (up to $75 \mathrm{~mm}$ ) around the pipe (Fig. 4). With a relatively big thickness of pipes, welding is performed in a $2 \cdots 3$ motion around the pipe and with a variable speed of movement of the electrode to obtain a complete seam profile without defects.

After welding the pipe edges, the mobile device is returned to its original place and fixed with the installed bolts. With the help of adjustable units, at the first stage, grinding wheels come into contact with the weld, and then deforming rollers that strengthen the outer surface of the seam. For complete processing of the more loaded part of the weld and the base metal, the working surfaces of the grinding wheels and deforming rollers coincide with the outer surface of the weld. In both of these operations, the cleaning unit continuously removes the waste of mechanical processing from the treated surface. 


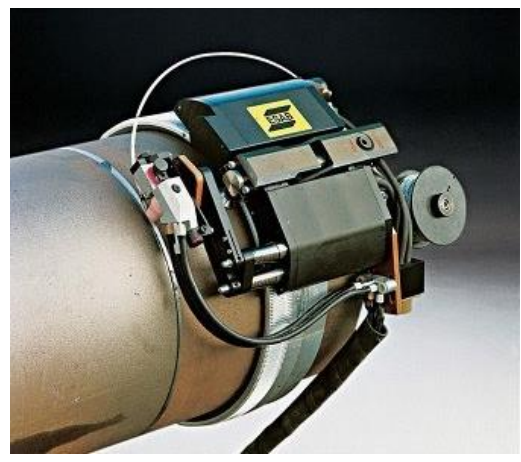

Fig. 4. General view of the welding machine PRO 100 during the welding process

At the last operation, anti-corrosion protective paste of the Belzona FN10/32 brand is applied [26]. It is applied to the weld surface and the transition section of the base metal with the help of a cleaning unit brush.

Five consecutive technological operations for pipe welding have their own technical indicators, which are interrelated and are in functional relations with geometric, material science, regime and climatic parameters, which involves the identification of these regression equations in order to determine the optimal values of the indicators. In this case, it is possible to obtain a general multiparameter function, which is advisable to represent systems of parametric equations and choose from these systems the option that is significant and paramount. This will give a possibility to obtain the operation indicators' optimal values, which will ensure high reliability and bearing capacity of the gas pipeline, and prolong its service life. As a result, it is possible to get a mathematical model of the pipe welding process and develop the necessary software.

\section{Conclusion}

The increased volume of engineering work on the design and laying of the GTS main pipelines brings new requirements for ensuring reliable operation of these large engineering structures. To implement this study, it is necessary to perform the following work:

- Study, analysis and classification of all possible defects and damages of critical structural elements of GTS working, which include welded pipe joints.

- Development of new design and technological measures to improve their performance over the pipeline service life.

- On the basis of the activities undertaken by points 1 and 2 to create a mathematical model of these technological procedures in order to use in the projected GTS gas pipelines.

This work has been carried out in the frame of "Preservation and development of the research laboratory of natural-mathematical modeling of construction tasks" and "Preservation and development of the research laboratory of construction and urban economy" programs financed by Science Committee of Republic of Armenia.

\section{References}

1. M.G. Stakyan, A.A. Kazaryan, Yu.A. Kazaryan, Bullettin of the Union of builders of Armenia, Proceedigs of scientific papers 2, 85-95 (2016). 
2. M. G. Stakyan, A.A. Kazaryan, Yu.A. Kazaryan, Bulletin of NUACA 3(52), 63-66 (2016).

3. M. G. Stakyan, A. A. Kazaryan, Yu. A. Kazaryan, Scientific Papers of NUACA 2(64), 120-125 (2016).

4. V. I. Trufyakov, Fatigue of welded joints (Naukova Dumka, Kiev, 1973).

5. V. I. Pokhmursky, Corrosion fatigue of metals (Metallurgy, Moscow, 1985).

6. S.A. Kurkin, The strength of welded thin-walled vessels operating under pressure (Mashinostroenie, Moscow, 1986).

7. N.V. Oleinik, A.V. Volchev, S. V. Bershak, et al. Calculation of machine parts for corrosion fatigue (Technika, Kiev, 1990).

8. N. V. Pirumyan, H. A. Khazaryan, M.G. Stakyan, Study of work reliability of gas subsurface storage by the method of finite elements, Proceedings of the 10th Int. Conf. on Contemporary Problems of Architecture and Construction (2018) 76-78.

9. N.V. Pirumyan, M.G. Stakyan, G.Sh. Galstyan, Key Engineering Materials 828, 115-120 (2020).

10. N.V. Pirumyan, M.G.Stakyan, G.Sh. Key Engineering Materials 828, 121-128 (2020).

11. N.V. Pirumyan, M.G. Stakyan, IOP Conf. Se.: Materials Sci. Eng. 698, 066022 (2019).

12. O.Yu. Steklov, The strength of welded structures in aggressive environments (Mashinostroenie, Moscow, 1976).

13. N.V. Pirumyan, M.G. Stakyan, IOP Conf. Se.: Materials Sci.Eng. 698, 022077 (2019).

14. I.V. Kudryavtsev, N.E. Naumchenov, Fatigue of welded structures (Mashinistroyenie, Moscow, 1976).

15. A. F. Dashchenko, V.S. Kravchuk, V.D. Iorgachev, Bearing capacity of reinforced machine part (Astroprint Odessa, 2004).

16. N.V. Pirumyan, M.G.Stakyan, H. A. Khazaryan, IOP Conf. Se.: Materials Sci.Eng. 1083, 012031 (2021).

17. N.V. Pirumyan, M.G. Stakyan, IOP Conf. Ser.: Mater. Sci. Eng. 913, 022006 (2020).

18. N.V. Pirumyan, M.G. Stakyan, IOP Conf. Ser.: Mater. Sci. Eng. 913, 022036 (2020).

19. N.V. Pirumyan, M.G. Stakyan, IOP Conf. Ser.: Mater. Sci. Eng. 913, 022035 (2020).

20. H.A. Khazaryan, S.S. Chibukhchyan, M.G. Stakyan, Improving the reliability of the gas transmission system (GTS) according to the criteria of structural strength and vibration resistance, Proceedings of 8th International Conference on Contemporary Problems of Architecture and Construction, (2016) 168-170.

21. M.S. Torosyan, N.V. Pirumyan, M.G. Stakyan, Bulletin of NUACA 1 (66), 58-66 (2020)

22. N.V. Pirumyan, M.G. Stakyan, Scientific Papers of NUACA 2 (77), 130-140 (2020).

23. N.V. Pirumyan, M.G. Stukyan, E3S Web of Conferences 97, 04027 1-9 (2019).

24. N.V. Pirumyan, M.G.Stakyan, H.A. Khazaryan, IOP Conf. Se.: Materials Sci.Eng. 1083, 012031 (2021).

25. Information on https://ruba630.pro(stat)/svarka-trub-630-mm/

26. Information on https://www.belzona.com/ru/index.aspx 